\title{
Nanocrystallization in Si:H and quantum size effect on optical gap*
}

\author{
DEBAJYOTI DAS \\ Energy Research Unit, Indian Association for the Cultivation of Science, Jadavpur, Calcutta \\ 700032, India
}

\begin{abstract}
Interruption of growth and H-plasma exposure on stacking layers of Si:H film resulted in a remarkable change in material properties. Widening of optical gap and increase in dark conductivity were simultaneous with the reduction in photoconductivity, bonded hydrogen content and optical absorption. An associated change in the network structure from amorphous towards crystalline was observed. Enhanced dose of plasma exposure resulted in the gradual lowering in the size of nanograins and increase in their number density. Systematic widening in optical gap during dehydrogenation of the network appears to be a unique feature related to amorphous semiconductors, which suggests nanocrystallization and quantum size effect in hydrogenated binary alloy.
\end{abstract}

Keywords. Interrupted growth; stacking layer; $\mathrm{H}$-plasma exposure; wide band gap; nanocrystallization and quantum size effect.

\section{Introduction}

Recent reports on visible photoluminescence (Canham 1990; Takagi et al 1990; Liu et al 1994), resonant tunneling (Fortunate et al 1989; Tsu et al 1990) and optical gap widening (Furukawa and Miyasato 1988) from ultrafine silicon structures have stimulated both experimental as well as theoretical investigations of quantum confinement effects in silicon. Nanocrystalline silicon (nc-Si) of grain size less than $10 \mathrm{~nm}$ has the potential for application to opto-electronics and ultra large scale integrated circuits(ULSI). A major challenge lies in the fabrication of regular arrays of quantum wires in silicon of controlled size and distribution which would enhance the understanding of the physics of this structure. For systematic technological development, it is first of all necessary to investigate the mechanism of nucleation and nanocrystallization in the fabrication of $\mathrm{nc}-\mathrm{Si}$. We have started an extensive and comprehensive experiment to investigate the nucleation and growth mechanism of nc-Si by solid state chemical reaction at the growth zone, a novel technique called 'chemical annealing' (Das et al 1991; Shirai et al 1991).

\section{Experimental}

Hydrogenated silicon ( $\mathrm{Si}: \mathrm{H})$ films were prepared from $\left(\mathrm{SiH}_{4}+\mathrm{H}_{2}\right)$-plasma in a capacitively coupled r.f. glow discharge single chamber reactor indigenously made of stainless steel and connected to a turbomolecular pump as well as a booster-rotary combination (Das 1995a). The residence time of the reacting gases in the deposition chamber was controlled by mechanical throttle valves. Steady H-plasma was attained from 100 SCCM constant flow of $\mathrm{H}_{2}$ at an r.f. power density of $45 \mathrm{~mW} / \mathrm{cm}^{2}$. Thin layers ( $\left.L \AA\right)$ of a-Si:H film were grown by introducing $\mathrm{SiH}_{4}$ into the $\mathrm{H}$-plasma and the growth was interrupted periodically by terminating the $\mathrm{SiH}_{4}$ flow at regular intervals. Separate

\footnotetext{
* Paper presented at the poster session of MRSI AGM VI, Kharagpur, 1995
} 
dose of $\mathrm{H}_{2}$ was introduced sequentially to maintain a constant pressure of 0.8 Torr in the reaction chamber during deposition. The flow synchronization was maintained with the help of pneumatic valves controlled by electronic timers. Each layer of $L \AA$, immediately after deposition, was allowed to be exposed to continuous and steady $\mathrm{H}$-plasma for a fixed period of time $t_{\mathrm{p}}$, for chemical annealing treatment by atomic $\mathrm{H}$ of the plasma. Repetition of the cycle of film deposition and H-plasma annealing for several times resulted in a thicker film $(d \AA)$. To study the effects of chemical annealing treatment by atomic $\mathbf{H}$ of the plasma at the growth zone, films were prepared by changing the plasma exposure time $\left(t_{\mathrm{p}}\right)$ on stacking layers of different thicknesses $(L)$ at various deposition temperatures $\left(T_{s}\right)$.

Samples were characterized by optical, electrical as well as structural studies. Films were prepared on Corning 7059 glass substrates for optical and electrical measurements and on single-crystal $\mathrm{Si}$ wafers for infrared absorption studies, at the same deposition run and efforts were made to maintain almost identical film thicknesses for different samples. For electron-transmission and -diffraction studies, films were deposited on carbon-coated copper microgrids by separate deposition run.

\section{Results and discussion}

At a substrate temperature of $250^{\circ} \mathrm{C}$, a set of films were prepared by changing the H-plasma exposure time $\left(t_{\mathrm{p}}\right)$, keeping the stacking layer thickness $(L)$ fixed at around 10 $\AA$. The optical density data of the samples was obtained from the transmission measurement in the UV-visible region by a double beam spectrophotometer. The reflectance was found to be almost unchanged for the set of samples. Figure 1 represents

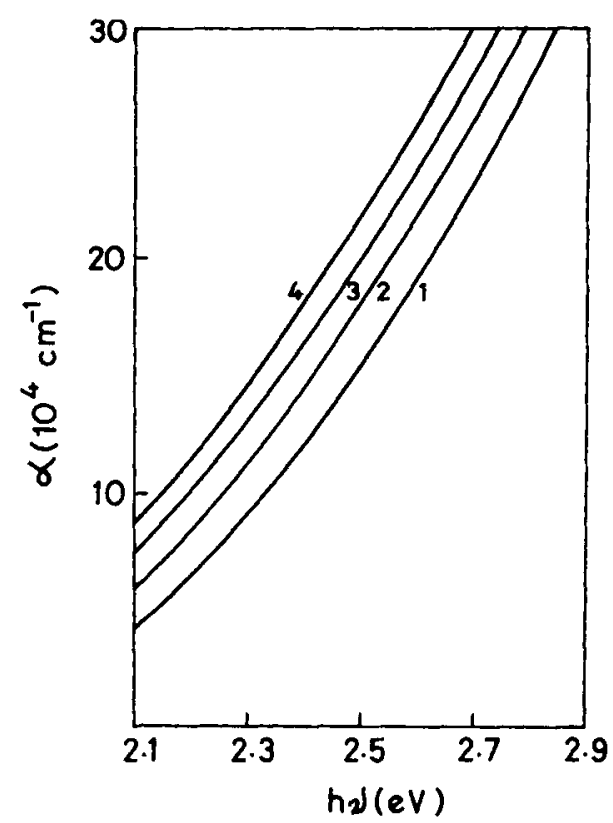

Figure 1. UV-visible absorption coefficient spectra of Si: $\mathrm{H}$ films prepared at $T_{\mathrm{s}}=250^{\circ} \mathrm{C}$ with stacking layer thickness, $L=10 \AA$ and exposed to $H$-plasma for $t_{\mathrm{p}}$ sec. Curves $1,2,3$ and 4 are for $t_{\mathrm{p}}=0,30,40$ and $50 \mathrm{sec}$ respectively. 


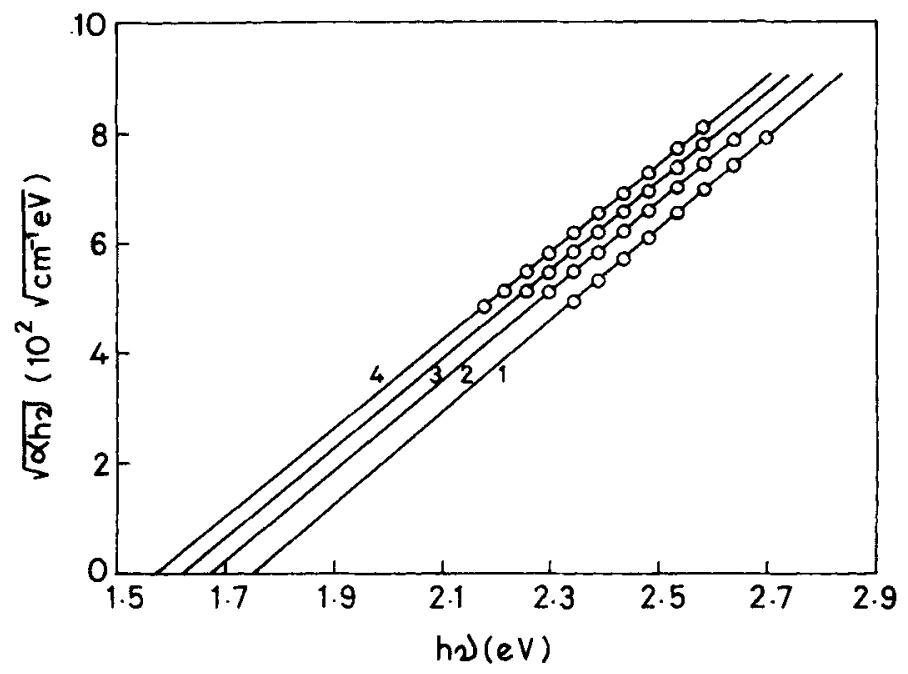

Figure 2. Tauc's plots for Si: $\mathrm{H}$ films prepared at $T_{\mathrm{s}}=250^{\circ} \mathrm{C} . L=10 \AA$ and with different $t_{\mathrm{p}}$. Curves $1,2,3$ and 4 are for $t_{p}=0,30,40$ and $50 \mathrm{sec}$ respectively.

Table 1. Properties of $\mathrm{Si}: \mathrm{H}$ films prepared by interrupted growth and $\mathrm{H}$-plasma exposure at $T_{\mathrm{s}}=250^{\circ} \mathrm{C}$.

\begin{tabular}{rcccccc}
\hline $\begin{array}{l}t_{\mathrm{p}} \\
(\mathrm{sec})\end{array}$ & $\begin{array}{c}E_{\mathrm{g}} \\
(\mathrm{eV})\end{array}$ & $\begin{array}{c}\mathrm{B} \\
\left(\mathrm{cm}^{-1 / 2} \mathrm{eV}^{-1 / 2}\right)\end{array}$ & $\begin{array}{c}\mathrm{C}_{\mathrm{H}} \\
(\mathrm{at} . \%)\end{array}$ & $\begin{array}{c}\sigma_{\mathrm{D}} \\
\left(\Omega^{-1} \mathrm{~cm}^{-1}\right)\end{array}$ & $\begin{array}{c}\Delta E_{\mathrm{D}} \\
(\mathrm{eV})\end{array}$ & $\begin{array}{c}\sigma_{\mathrm{Ph}} \\
\left(\Omega^{-1} \mathrm{~cm}^{-1}\right)\end{array}$ \\
\hline 0 & 1.75 & 833 & $13 \cdot 8$ & $8.2 \mathrm{E}-11$ & 0.95 & $5 \cdot 7 \mathrm{E}-5$ \\
30 & 1.67 & 812 & $10 \cdot 7$ & $4.8 \mathrm{E}-10$ & 0.90 & $4.7 \mathrm{E}-5$ \\
40 & 1.62 & 806 & 7.6 & $2 \cdot 1 \mathrm{E}-9$ & 0.86 & $1.6 \mathrm{E}-5$ \\
50 & 1.57 & 802 & 6.2 & $8.4 \mathrm{E}-9$ & 0.82 & $9 \cdot 8 \mathrm{E}-6$ \\
\hline
\end{tabular}

the absorption coefficient spectrum of the films in the interference free region. A gradual rise in the visible absorption $(\alpha)$ was pronounced for samples exposed to $\mathrm{H}$-plasma for a longer period of time. The absorption coefficient $(\alpha)$ near the optical absorption edge can be well approximated by Tauc's formula:

$$
\alpha h v \propto\left(h v-E_{\mathrm{g}}\right)^{2} .
$$

The UV-visible absorption spectra in Tauc's plot $\left((\alpha h v)^{1 / 2}\right.$ vs $\left.h v\right)$ was found to shift almost parallely towards lower energy as shown in figure 2 . A systematic narrowing in optical gap ( $E_{\mathrm{g}}$, Tauc gap) as obtained from the extrapolation of the straight region of the above plot to the energy axis at $\alpha=0$ and the associated minor lowering in the slope (B) of the above plot, were the effects of increase in $t_{\mathrm{p}}$ i.e. of extended atomic $\mathrm{H}$ treatment on stacking layers.

The bonded hydrogen content $\left(\mathrm{C}_{\mathrm{H}}\right)$ was estimated from the intensity of infrared absorption in wagging mode vibration (around $630 \mathrm{~cm}^{-1}$ ). Elimination of hydrogen from the $\mathrm{Si}: \mathrm{H}$ network was observed due to the introduction of interruption in growth and H-plasma exposure on stacking layers and was found to be gradual with $t_{\mathrm{p}}$ as shown in table 1 . The $\mathrm{H}$-plasma treated samples prepared at $250^{\circ} \mathrm{C}$ had mostly the monohydride silicon bonding configuration as estimated from IR absorption spectra. 


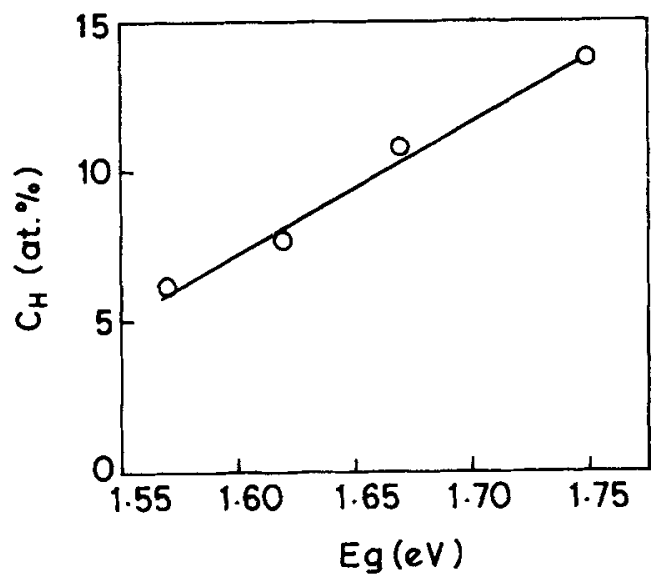

Figure 3. Variation of optical gap $\left(E_{\mathrm{g}}\right)$ vs bonded $\mathrm{H}$-content $\left(\mathrm{C}_{\mathrm{H}}\right)$, showing their direct linear proportionality in $\mathrm{Si}: \mathrm{H}$ films prepared by interrupted growth and $\mathrm{H}$-plasma treatment at $T_{\mathrm{s}}=250^{\circ} \mathrm{C}$.

The $\mathrm{Si}-\mathrm{H}$ stretching mode absorption peak was mostly around $2000 \mathrm{~cm}^{-1}$, however, shifted to $2010 \mathrm{~cm}^{-1}$ at $t_{\mathrm{p}}=50 \mathrm{sec}$. The narrowing of optical gap, $E_{\mathrm{g}}$ of Si:H films obtained by $\mathrm{H}$-plasma exposure was found to have a linear relation to the elimination of bonded hydrogen from the network as shown in figure 3.

The dark conductivity $\left(\sigma_{\mathrm{D}}\right)$ of the samples was measured at a vacuum of $10^{-6}$ Torr after annealing the sample at $150^{\circ} \mathrm{C}$ for $1 \mathrm{~h}$, and the photoconductivity $\left(\sigma_{\mathrm{Ph}}\right)$ was measured by illuminating the samples by white light of $100 \mathrm{~mW} / \mathrm{cm}^{2}$ intensity. $\sigma_{\mathrm{D}}$ was found to increase gradually along with the simultaneous reduction in $\sigma_{\mathrm{Ph}}$ with the increase in the dose of hydrogen plasma treatment. However, the dark conductivity activation energy, $\Delta E_{\mathrm{D}}$ was noticeably high, generally $\Delta E_{\mathrm{D}}>E_{\mathrm{g}} / 2$ as shown in table 1 .

Transmission electron microscope (TEM) studies were done on the samples. The electron micrograph was almost featureless, and the diffraction pattern was a halo for films prepared without growth interruption. Interruption in growth and H-plasma treatment on stacking layers did not introduce any change in the diffraction pattern and electron micrographs. The amorphous nature of the material remained unaltered even at the highest dose of $\mathrm{H}$-plasma annealing i.e. at $t_{\mathrm{p}}=50 \mathrm{sec}$ for films prepared at $250^{\circ} \mathrm{C}$.

The results as described above are in close proximity with the experimental observations from our previous studies as reported earlier (Das et al 1991; Shirai et al 1991). In our earlier studies a novel concept of 'chemical annealing' by atomic hydrogen was introduced to promote the network propagation process and to enhance the rigidity of Si-network structure. An intense flux of atomic hydrogen was generated by microwave plasma, compared to that by r.f. plasma in the present investigation. In films prepared by alternating deposition and chemical annealing at $T_{\mathrm{s}}$ above $300^{\circ} \mathrm{C}, \mathrm{C}_{\mathrm{H}}$ was reduced remarkably down to even 1 at. \% along with an extremely low $E_{\mathrm{g}}$ of $1.50 \mathrm{eV}$. From Raman scattering measurements, it was observed that the TO band shifted to 490 $\mathrm{cm}^{-1}$ along with the minor narrowing of band width (FWHM), indicating increased rigidity of the network. However, the TA band at around $150-200 \mathrm{~cm}^{-1}$ increased slightly in intensity. No sign of crystallinity was identified even in the film containing $\mathrm{C}_{\mathrm{H}}$ of 1 at. \%. The smooth logarithmic tails with rather sharp slopes, as obtained by 


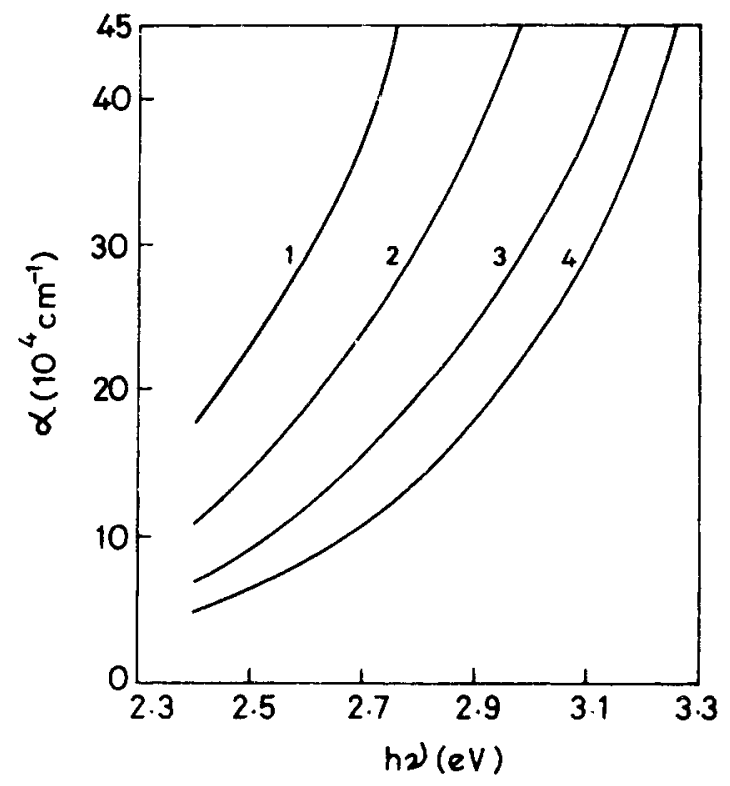

Figure 4. UV-visible absorption coefficient spectra of Si:H films prepared at $T_{\mathrm{s}}=100^{\circ} \mathrm{C}$, $L=5 \AA$ and with different $t_{\mathrm{p}}$. Curves $1,2,3$ and 4 are for $t_{\mathrm{p}}=0,20,30$ and $40 \mathrm{sec}$ respectively.

constant photocurrent measurement (CPM) were further experimental evidences to support the absence of any phase separation in well-annealed films. The tail state absorption curves were shifted towards a lower photon energy region with the reduction of $\mathrm{C}_{\mathrm{H}}$, similar to the shift of the Tauc's plots. Most of the annealed samples were found to exhibit a dark conductivity larger than that of the conventionally prepared samples by r.f. glow discharge and $\Delta E_{\mathrm{D}}$ was noticeably high, generally $\Delta E_{\mathrm{D}}>E_{\mathrm{g}} / 2$. The non-dispersive minority (hole) carrier transport exhibited from the time-of-flight (TOF) study clearly demonstrated the significant narrowing of the localized states in the vicinity of the valence band and fundamentally the reduction in the degree of disorder in the Si-Si network obtained by the modulation of the surface through alternate deposition and chemical annealing by atomic hydrogen at the growth zone (Das et al 1991).

Substrate temperature $\left(T_{s}\right)$ has its enormous influence on the structural relaxation process over the effect of chemical annealing by atomic hydrogen at the growth zone. At a low $T_{\mathrm{s}}$ of $100^{\circ} \mathrm{C}$, a set of films were prepared by changing $t_{\mathrm{p}}$, keeping $L$ fixed at around $5 \AA$. The deposition rate of the films was about $30 \AA / \mathrm{min}$. Such a low rate of deposition at this low temperature ensured the CVD-like growth condition. The absorption coefficient spectrum of the films has been presented in figure 4. A gradual reduction in the visible absorption along with a systematic shift of the onset of optical absorption towards higher energy was pronounced for samples exposed to $\mathrm{H}$-plasma for longer period of time. Almost parallel shift of the Tauc's plots towards higher energies (figure 5) indicated the systematic widening of the optical gap $\left(E_{\mathrm{g}}\right)$ due to extended $\mathrm{H}$-plasma exposure on stacking layers. This is the noticeable difference obtained in the material properties of the films compared to those prepared at higher $T_{\mathrm{s}}\left(250^{\circ} \mathrm{C}\right)$ due to similar type of $\mathrm{H}$-plasma treatment. and presents the central point of discussion in this 
current report. The nature of changes in the slope (B) of Tauc's plots was similar at two different $T_{s}$, although, at lower $T_{s}\left(100^{\circ} \mathrm{C}\right)$ lowering in B was little larger.

Film prepared at such a low temperature $\left(100^{\circ} \mathrm{C}\right)$ without any growth interruption, was of large hydrogen content of about 25 at. \% and was not free from polyhydride bonding, as expected. The large optical gap of $1.83 \mathrm{eV}$ was compatible with the amount and nature of hydrogen bonding. On introduction of interruption in growth and $\mathrm{H}$-plasma treatment, a gradual reduction in $\mathrm{C}_{\mathrm{H}}$ was obtained with increase in $t_{\mathrm{p}}$, as shown in table 2, following the regular consequences of atomic $\mathrm{H}$ exposure on stacking layers. Simultaneous enhancement in polyhydride type of bonding was observed in the stretching mode vibration as shown in figure 6 . At $t_{\mathrm{p}}=40 \mathrm{sec}$, stretching mode absorption band appeared exclusively around $2100 \mathrm{~cm}^{-1}$. The intensity of both the $\mathrm{SiH}_{2}$ bending and $\left(\mathrm{SiH}_{2}\right)_{n},(n>1)$ wagging mode absorption around $880 \mathrm{~cm}^{-1}$ and 840 $\mathrm{cm}^{-1}$ respectively increased with $t_{\mathrm{p}}$, however, their relative intensity did not change much (Das 1994). The linear relation between $E_{\mathrm{g}}$ and $\mathrm{C}_{\mathrm{H}}$, shown in figure 7, as obtained for the $\mathrm{Si}: \mathrm{H}$ films prepared at $100^{\circ} \mathrm{C}$ was exactly opposite to that (figure 3) obtained for films prepared at $250^{\circ} \mathrm{C}$. This opposite nature of changes makes the present investigation interesting. The gradual increase in $\sigma_{\mathrm{D}}$ and decrease in $\sigma_{\mathrm{Ph}}$ at higher $t_{\mathrm{p}}$ followed the regular characteristics of $\mathrm{H}$-plasma annealing. The magnitude of $\Delta E_{\mathrm{D}}$ was sufficiently large all along as if the Fermi level was pinned almost at the middle of the band gap. Electron micrograph was almost featureless and diffraction pattern was a halo for films prepared without growth interruption. However, on H-plasma exposure very small nanograins were found to be embedded in an amorphous network. Almost homogeneous distribution of nanocrystalline grains ( $50 \AA$ to $100 \AA$ in diameter) is depicted in figure $8 \mathrm{a}$ and the corresponding electron diffraction pattern in figure $8 \mathrm{~b}$.

The optical gap of binary $\mathrm{Si}: \mathrm{H}$ materials increases almost linearly with increasing $\mathrm{H}$-content as observed in case of films prepared at $250^{\circ} \mathrm{C}$ and presented in figure 3 . The result could be explained by the simple alloying effect (Nama et al 1983). Furukawa and Matsumoto (1985), however, showed that optical gap could be increased by increasing the poly-silane chains along with the increase in $\mathrm{H}$-content itself. They showed a good correlation between the optical gap and the increase in relative intensity of absorption at $845 \mathrm{~cm}^{-1}$ to that at $890 \mathrm{~cm}^{-1}$ which are due to $\left(\mathrm{SiH}_{2}\right)_{n},(n>1)$ wagging and $\mathrm{SiH}_{2}$ bending mode absorption respectively. In contrast, for films prepared at a low temperature of $100^{\circ} \mathrm{C}$, the relative intensity of absorption due to the above mentioned two vibrational modes did not change noticeably, and so the inverse relation between the $\mathrm{H}$-content and the optical gap as presented in figure 7 appears to be nonconventional and interesting. Rather, increase in polysilane formation and the gradual shift of the stretching mode absorption from $2010 \mathrm{~cm}^{-1}$ to $2100 \mathrm{~cm}^{-1}$ along with the reduction in $\mathrm{H}$-content indicated the formation of microcrystalline $\mathrm{Si}: \mathrm{H}$ (Asano 1990; Boland and Parson 1992; Jang et al 1992). However, from electrical conductivity measurement microcrystallization was not acknowledged by the minor increment in $\sigma_{\mathrm{D}}$ and the large magnitude of its activation energy, $\Delta E_{\mathrm{D}}$ (table 2). A decrease in $\alpha$ in the UV-visible region has often been observed in the transition from amorphous to microcrystalline phases. However, in such a transition, a sharp deviation from linearity in Tauc's plot is a regular feature, and it causes large ambiguity in determining the optical gap. Conversely, for the present set of samples, reasonably good linearity was observed in the $(\alpha h v)^{1 / 2}$ vs $h v$ plots (figure 5). An almost parallel shift of the linear plots indicated a systematic widening of the optical gap for films prepared at fixed stacking layer thickness $(L)$ and exposed to H-plasma for extended period of time $\left(t_{\mathrm{p}}\right)$. A gradual 


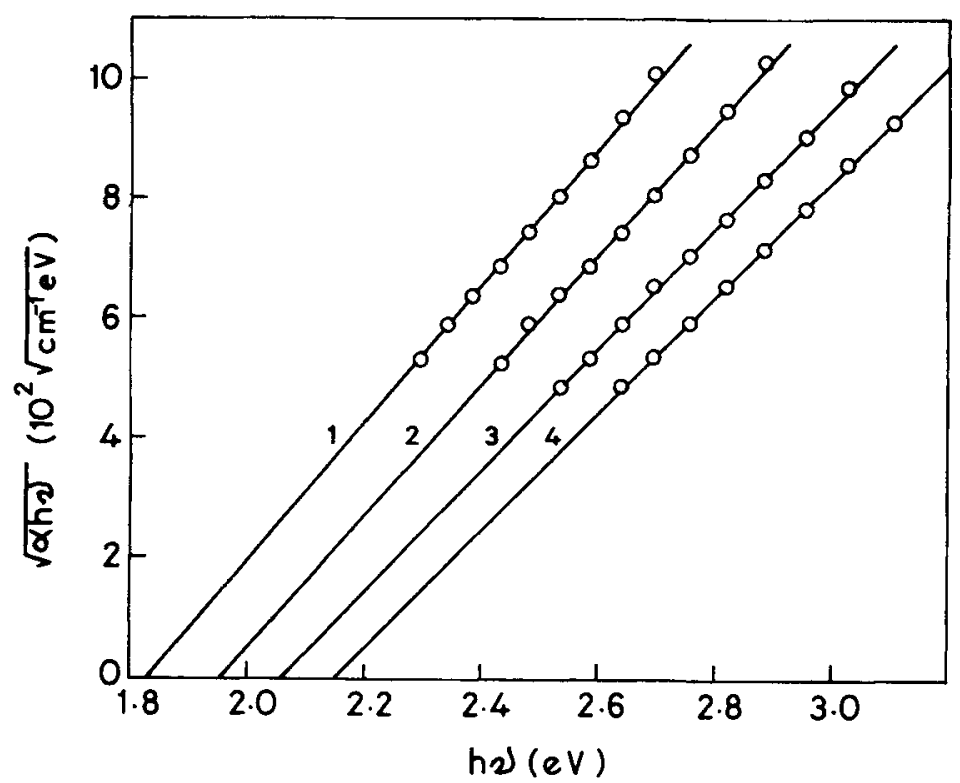

Figure 5. Tauc's plots for Si:H films prepared at $T_{\mathrm{s}}=100^{\circ} \mathrm{C}, L=5 \AA$ and with different $t_{\mathrm{p}}$. Curves $1,2,3$ and 4 are for $t_{p}=0,20,30$ and 40 sec respectively.

Table 2. Properties of $\mathrm{Si}: \mathrm{H}$ films prepared by interrupted growth and $\mathrm{H}$-plasma exposure at $T_{\mathrm{s}}=100^{\circ} \mathrm{C}$.

\begin{tabular}{ccccccc}
\hline $\begin{array}{l}t_{\mathrm{p}} \\
(\mathrm{sec})\end{array}$ & $\begin{array}{c}E_{\mathrm{g}} \\
(\mathrm{eV})\end{array}$ & $\begin{array}{c}\mathrm{B} \\
\left(\mathrm{cm}^{-1 / 2} \mathrm{eV}^{-1 / 2}\right)\end{array}$ & $\begin{array}{c}\mathrm{C}_{\mathrm{H}} \\
(\mathrm{at} . \%)\end{array}$ & $\begin{array}{c}\sigma_{\mathrm{D}} \\
\left(\Omega^{-1} \mathrm{~cm}^{-1}\right)\end{array}$ & $\begin{array}{c}\Delta E_{\mathrm{D}} \\
(\mathrm{eV})\end{array}$ & $\begin{array}{c}\sigma_{\mathrm{Ph}} \\
\left(\Omega^{-1} \mathrm{~cm}^{-1}\right)\end{array}$ \\
\hline 0 & 1.83 & 1139 & $25 \cdot 1$ & $7.9 \mathrm{E}-10$ & 0.92 & $9 \cdot 7 \mathrm{E}-5$ \\
20 & 1.95 & 1082 & $17 \cdot 5$ & $1 \cdot 1 \mathrm{E}-9$ & $0 \cdot 82$ & $8 \cdot 2 \mathrm{E}-6$ \\
30 & $2 \cdot 06$ & 1010 & $12 \cdot 5$ & $1.6 \mathrm{E}-9$ & $0 \cdot 81$ & $9 \cdot 3 \mathrm{E}-7$ \\
40 & $2 \cdot 15$ & 971 & $5 \cdot 1$ & $6 \cdot 7 \mathrm{E}-9$ & $0 \cdot 88$ & $1.0 \mathrm{E}-6$ \\
\hline
\end{tabular}

shift of the onset of optical absorption towards higher energy leading to a widening of the optical gap along with the simultaneous growth of nanostructures within the amorphous network suggests nanocrystallization and an associated three-dimensional quantum confinement of carriers in the electron-hole system.

At a particular parametric condition of the plasma, the dose of $\mathrm{H}$-plasma exposure on the growing $\mathrm{Si}: \mathrm{H}$ network could be controlled either by changing the plasma exposure time $\left(t_{\mathrm{p}}\right)$ or by regulating the stacking layer thickness $(L)$. At an intermediate temperature, $150^{\circ} \mathrm{C}$, a set of films were prepared by controlling both $L$ and $t_{\mathrm{p}}$ in steps. The results have been presented in table 3 . The nature of changes were found to have very close similarity to that for lower temperature $\left(100^{\circ} \mathrm{C}\right.$ ) samples (table 2$)$. Introduction of interruption in growth, systematic reduction in the stacking layer thickness and then the enhancement in the duration of plasma exposure resulted in a systematic lowering in the UV-visible absorption, widening in the optical gap as well as reduction in bonded hydrogen content in the network. The dark conductivity remained unaltered up to certain steps and then started increasing, however, dark Fermi level appeared to 


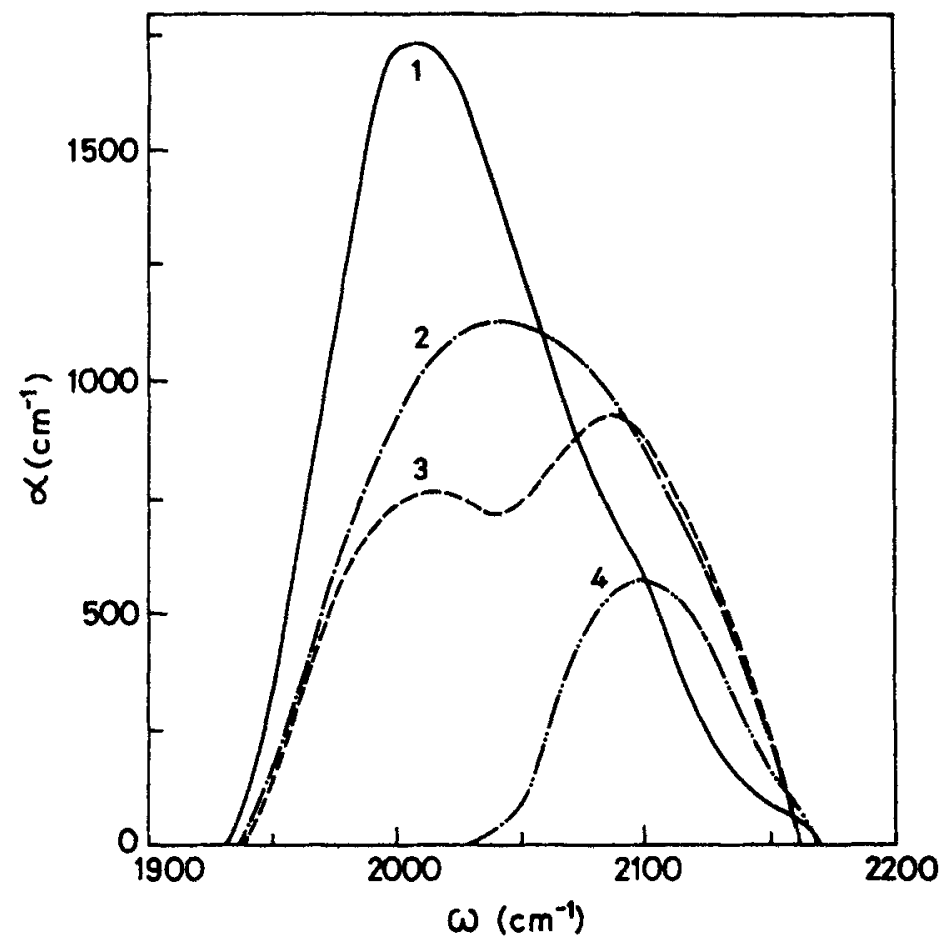

Figure 6. Infrared absorption coefficient spectra of stretching mode vibration for $\mathrm{Si}: \mathrm{H}$ films prepared at $T_{s}=100^{\circ} \mathrm{C}, L=5 \AA$ and with different $t_{\mathrm{p}}$. Curves $1,2,3$ and 4 are for $t_{\mathrm{p}}=0,20,30$ and 40 sec respectively.

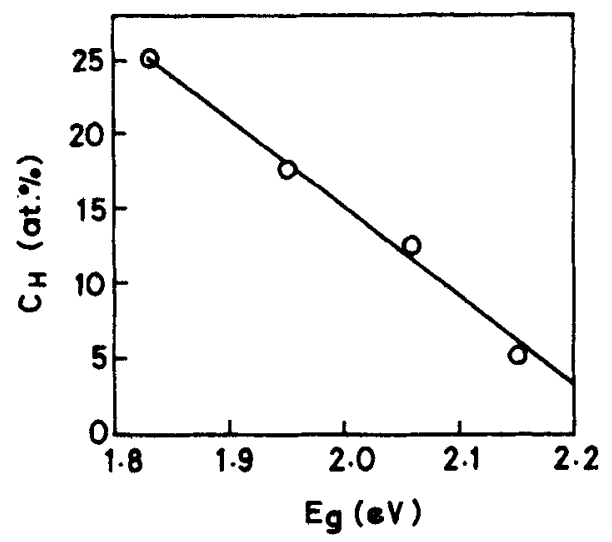

Figure 7. Variation of optical gap $\left(E_{q}\right)$ vs bonded $H$-content $\left(C_{H}\right)$, showing their inverse linear proportionality in $\mathrm{Si}: \mathrm{H}$ films prepared by interrupted growth and $\mathrm{H}$-plasma treatment at $T_{\mathrm{s}}=100^{\circ} \mathrm{C}$.

be pinned around the mid gap. At the onset of increasing $\sigma_{\mathrm{D}}$ (at $L=12 \AA, t_{\mathrm{p}}=30 \mathrm{sec}$ ), a low density and homogeneous distribution of nanograins (15-20 nm in diameter) embedded in the amorphous matrix was observed in the TEM micrograph as shown in figure 9a, and the corresponding diffraction pattern in figure $9 \mathrm{~b}$. Due to the enhancement in the dose of $\mathrm{H}$-plasma exposure (at $L=5 \AA, t_{\mathrm{p}}=30 \mathrm{sec}$ ), mostly high density 


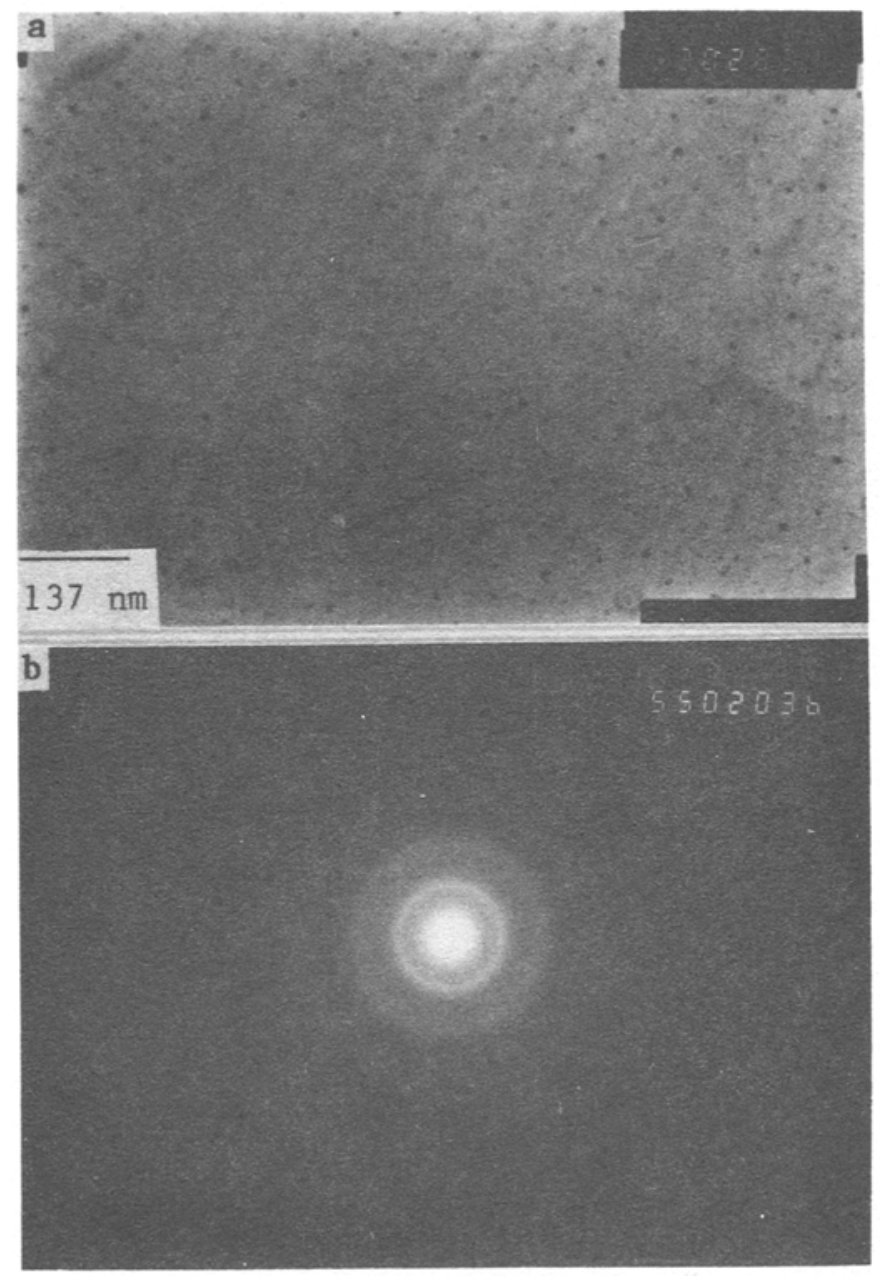

Figure 8. a. TEM micrograph and $\mathbf{b}$. electron diffraction pattern of $\mathrm{Si}: \mathrm{H}$ films prepared at $T_{\mathrm{s}}=100^{\circ} \mathrm{C}, L=5 \AA$ and with $t_{\mathrm{p}}=40 \mathrm{sec}$.

homogeneous and smaller size nanocrystallites $(5-10 \mathrm{~nm}$ in diameter) were found to be distributed on the TEM micrograph (figure 10a). The corresponding electron-diffraction pattern has been shown in figure $10 \mathrm{~b}$. A very wide gap $\left(E_{\mathrm{g}} \sim 2 \mathrm{eV}\right) \mathrm{Si}: \mathrm{H}$ material having sufficiently low $\mathrm{H}$-content $\left(\mathrm{C}_{\mathrm{H}} 5\right.$ at. \%), obtained on further enhancement in the dose of H-plasma treatment (at $L=5 \AA, t_{\mathrm{p}}=50 \mathrm{sec}$ ) contained a very dense and homogeneous distribution of nanocrystalline particles as observed in the TEM micrograph (figure 11a). The very sharp rings exhibited by the corresponding electron diffraction pattern (figure $11 \mathrm{~b}$ ) are the clear representatives of the prominent crystallinity. The increase in the optical gap with the decrease in the size of the nanocrystallites along with their increase in volume fraction could be explained qualitatively by the quantum size effect (Das 1995a).

Quantum confinement of electrons in the nanocrystals of porous silicon had been suggested by Canham (1990), to be responsible for the enhancement of the optical gap which leads to visible photoluminescence in this material. In mostly crystallized binary 
Table 3. Properties of $\mathrm{Si}: \mathrm{H}$ films prepared by interrupted growth and $\mathrm{H}$-plasma exposure at $T_{\mathrm{s}}=150^{\circ} \mathrm{C}$.

\begin{tabular}{lccccccc}
\hline $\begin{array}{l}t_{\mathrm{p}} \\
(\mathrm{sec})\end{array}$ & $\begin{array}{c}L \\
(\AA)\end{array}$ & $\begin{array}{c}E_{\mathrm{g}} \\
(\mathrm{eV})\end{array}$ & $\begin{array}{c}\mathrm{B} \\
\left(\mathrm{cm}^{-1 / 2} \mathrm{eV}^{-1 / 2}\right)\end{array}$ & $\begin{array}{c}\mathrm{C}_{\mathrm{H}} \\
(\mathrm{a} 1 . \%)\end{array}$ & $\begin{array}{c}\sigma_{\mathrm{D}} \\
\left(\Omega^{-1} \mathrm{~cm}^{-1}\right)\end{array}$ & $\begin{array}{c}\Delta E_{\mathrm{D}} \\
(\mathrm{eV})\end{array}$ & $\begin{array}{c}\sigma_{\mathrm{Ph}} \\
\left(\Omega^{-1} \mathrm{~cm}^{-1}\right)\end{array}$ \\
\hline- & - & 1.74 & 1053 & 17.5 & $2 \cdot 5 \mathrm{E}-1$ & 0.97 & $7 \cdot 6 \mathrm{E}-5$ \\
30 & 20 & 1.79 & 980 & 16.2 & $2.6 \mathrm{E}-10$ & 0.90 & $6 \cdot 1 \mathrm{E}-5$ \\
30 & 12 & 1.87 & 962 & 12.9 & $2 \cdot 4 \mathrm{E}-10$ & $0 \cdot 86$ & $2 \cdot 2 \mathrm{E}-5$ \\
30 & 5 & 1.93 & 924 & $9-5$ & $2.9 \mathrm{E}-8$ & 0.81 & $5 \cdot 1 \mathrm{E}-5$ \\
50 & 5 & 2.01 & 885 & 5.0 & $9 \cdot 2 \mathrm{E}-8$ & $0 \cdot 81$ & $9 \cdot 6 \mathrm{E}-7$ \\
\hline
\end{tabular}
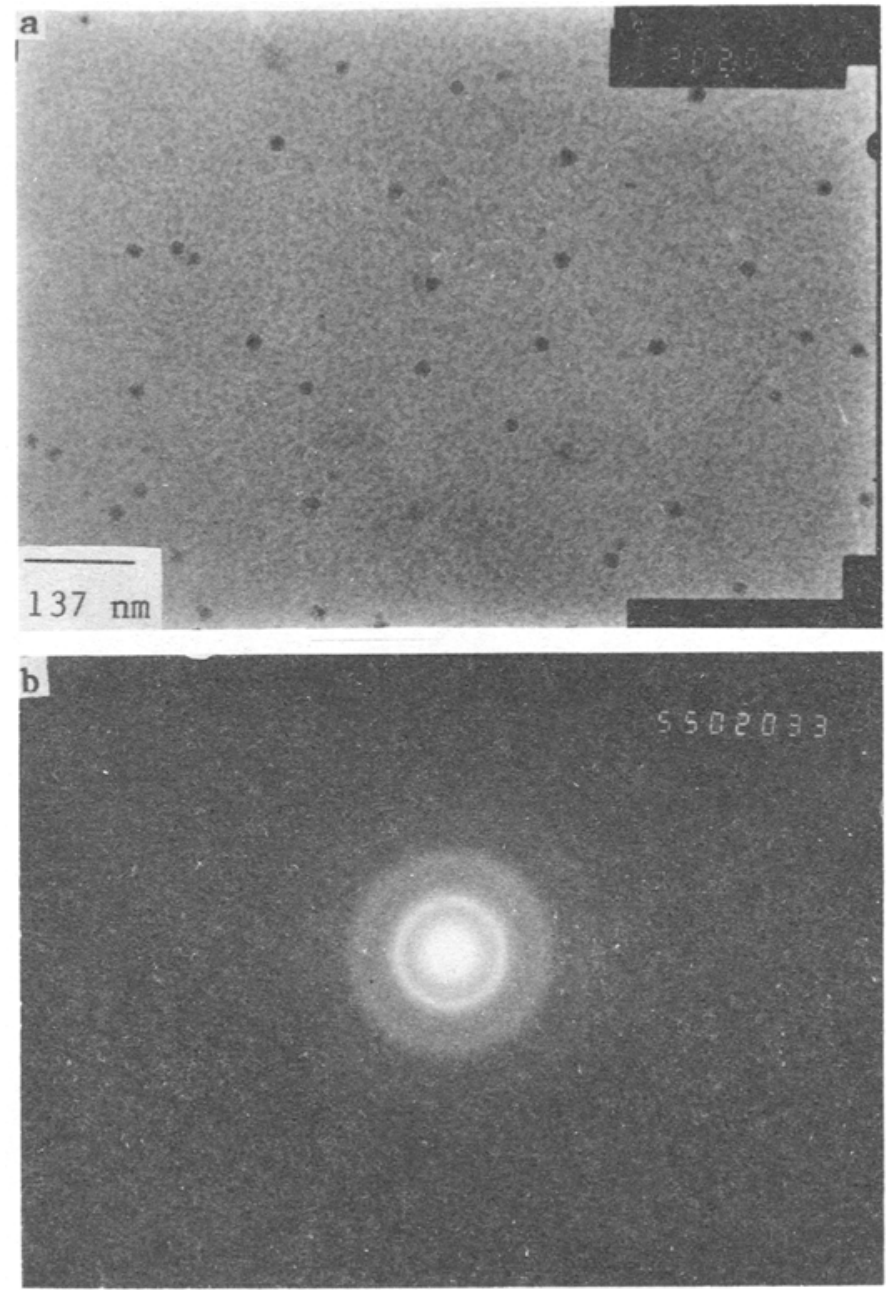

Figure 9. a. TEM micrograph and b. electron diffraction pattern of $\mathrm{Si}: \mathrm{H}$ films prepared at $T_{\mathrm{s}}=150^{\circ} \mathrm{C}, L=12 \AA$ and with $t_{\mathrm{n}}=30 \mathrm{sec}$.

$\mathrm{Si}: \mathrm{H}$ materials prepared by planar magnetron sputtering at a very low temperature, Furukawa and Miyasato (1988) explained the widening of the optical gap and the visible photoluminescence at room temperature by quantum size effect. Nanocrystallization of 

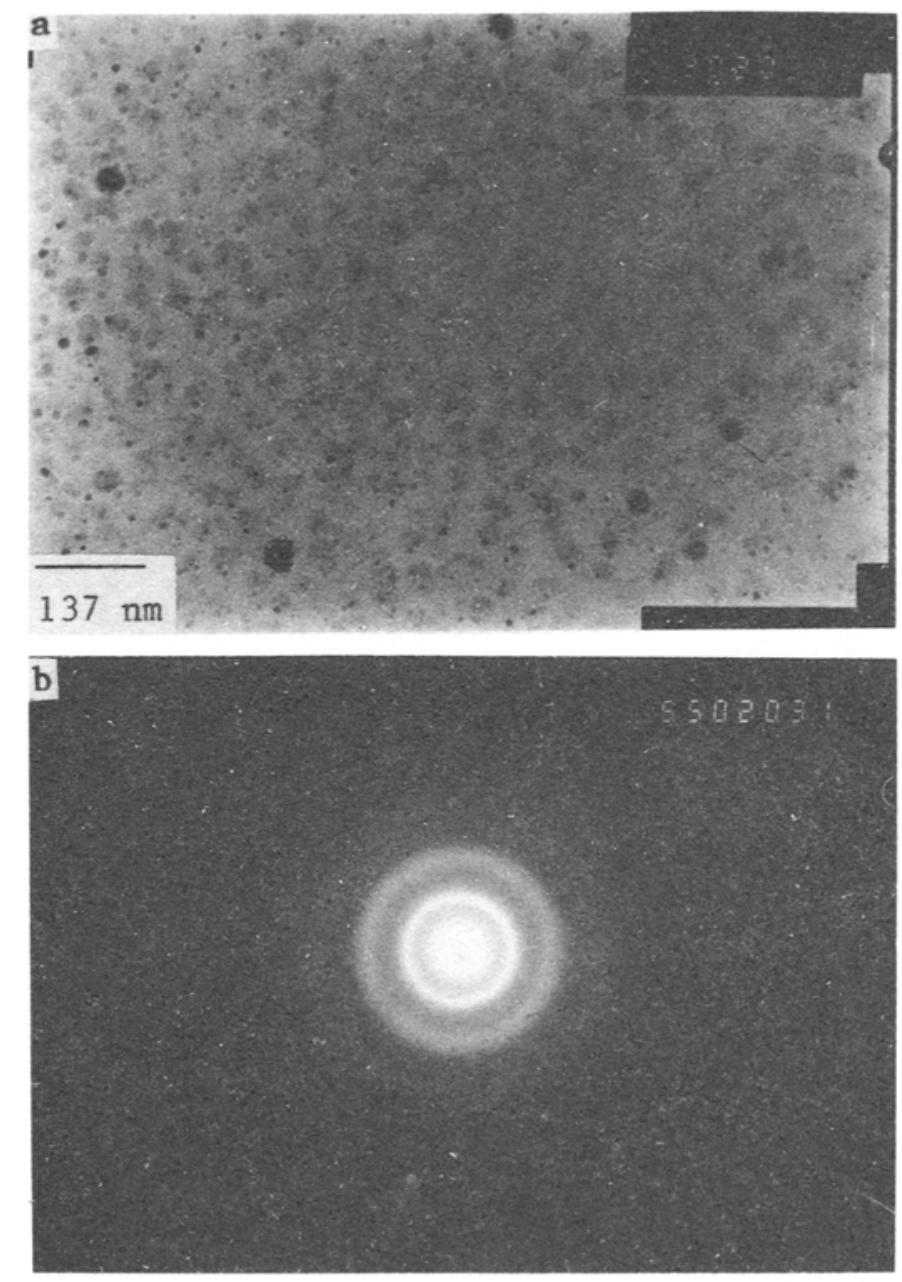

Figure 10. a. TEM micrograph and b. electron diffraction pattern of $\mathrm{Si}: \mathrm{H}$ films prepared at $T=150 \mathrm{C}, L=5 \AA$ and with $t_{\mathrm{p}}=30 \mathrm{sec}$.

$\mathrm{Si}: \mathrm{H}$ by very high frequency (VHF) plasma CVD was reported by Otobe and Oda (1992). Light emitting crystallites were prepared by plasma enhanced CVD (Liu et al 1994) and quantum size effect in nc-Si:H sublayers of the nc-Si:H/a-Si:H multilayered structure was reported (Tong et al 1995) to be responsible for the emission above the band gap of bulk crystal Si. Extensive theoretical work has been done on the energy gap of nanostructured Si crystallites (Ren and Dow 1992; Delley and Steigmeier 1993), the results of which show a trend of increasing band gap with decreasing crystallite size. According to the calculation by Brus (1984), the confinement energy for a spherical semiconducting crystal is roughly proportional to the reciprocal of the square of its size. In our present investigation, estimation of the exact size of the nanocrystals and their distinct differentiation was not done, however, the decrease in the size of the nanocrystallites along with the increase in their volume fraction appears to be consistent with the widening in optical gap as a consequence of the enhanced effects of quantum confinement of carriers in the nanostructured system. 

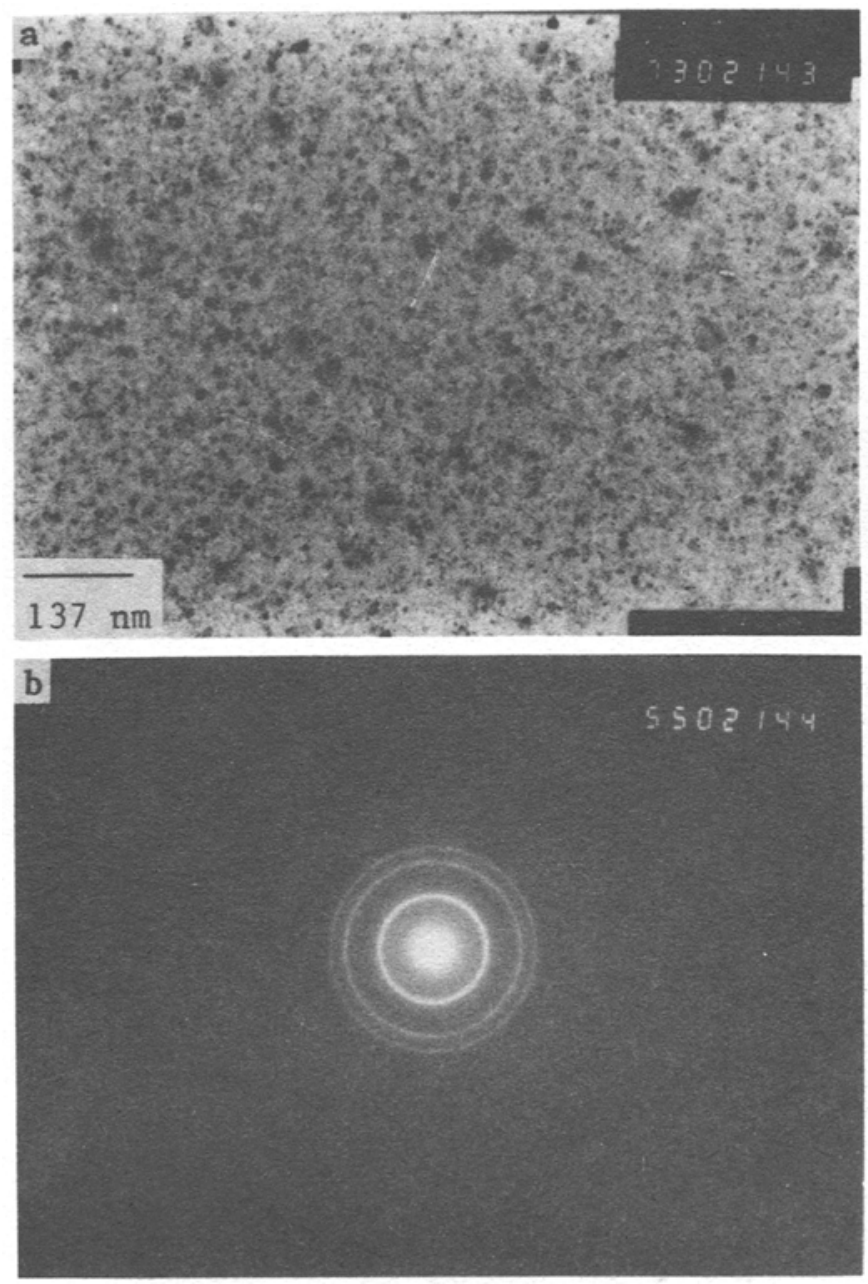

Figure 11. a. TEM micrograph and $b$. electron diffraction pattern of $\mathrm{Si}: \mathrm{H}$ films prepared at $T_{\mathrm{s}}=150^{\circ} \mathrm{C}, L=5 \AA$ and with $t_{\mathrm{p}}=50 \mathrm{sec}$.

The idea of the solid state chemical approach is to view the plasma as a supplier of chemically reactive species, with $\mathrm{Si}: \mathrm{H}$ material properties being determined mostly by chemical reactions taking place at the growing surface of the network i.e. at the growth zone where the network is supposed to remain in a quasiequilibrium state (Shimizu 1989; Winer 1990). The equilibrium and kinetics at the growing solid surface and plasma boundary could be smoothly controlled with the aid of a chemical mediator such as atomic hydrogen, due to strong chemical reactivity as well as diffusivity of monoatomic hydrogen in Si network (Das et al 1991; Shirai et al 1991). The final film structure is determined by the motion and elimination of excess hydrogen and the reduction in structural disorder. The stable structure occurs when there is sufficient hydrogen mobility to complete the reactions (Das 1995a,b). The subsurface zone of interaction or the penetration depth of atomic $\mathrm{H}$ during $\mathrm{H}$-plasma treatment is determined by its diffusion length $\left(L_{\mathrm{D}}\right)$ into the network, and is related to the diffusion 
coefficient $\mathrm{D}$ as:

$$
L_{\mathrm{D}}^{2}=4 D t
$$

At depth below $L_{\mathrm{D}}$ the bonded hydrogen is not in communication with the plasma hydrogen. At a specific parametric condition, the diffusion coefficient into the network is fixed. Then for a particular time of plasma exposure $t=t_{\mathrm{p}}$, the reduced stacking layer thickness should enhance the effect of plasma exposure. When the stacking layer thickness is of the order of diffusion length, i.e. at $L \sim L_{\mathrm{D}}$, the one way atomic $\mathrm{H}$ reaction should be complete, and after that some sort of transition may occur as the degree of structural order greatly exceeds that available in the amorphous network (Street 1991). Under such a condition nuclei for nanocrystallization are formed on the surface during $\mathrm{H}$-plasma exposure. During the next cycle of deposition, in the hydrogen-rich atmosphere, very small nanocrystallites consisting of several nuclei are formed at the interface (Otobe and Oda 1992). During the next cycle of $\mathrm{H}$-plasma treatment, atomic $\mathrm{H}$ diffuses through the network to the nanocrystallites and contributes to the grain growth and finally results in nanocrystalline Si particles embedded in an amorphous matrix. For thicker stacking layers atomic $\mathrm{H}$ probably reaches selectively to several nanocrystallites and larger size grains are produced, however, for thinner stacking layers atomic $\mathrm{H}$ reaches to most of the crystallites and a dense distribution of smaller size nanocrystalline Si particles are obtained. Extended $\mathrm{H}$-plasma treatment contributes improved nanocrystallinity with increased volume fraction. Such crystallization is associated with the sharp elimination of hydrogen from the network (Das 1995a, b).

Low substrate temperature could not provide sufficient hydrogen motion and consequently very good nanocrystallinity was not attained. At a higher substrate temperature, on the contrary, the as grown amorphous network was so rigid that growth interruption and the limited dose of $\mathrm{H}$-plasma exposure available at the present experimental configuration, was not able to make a phase transformation from amorphous to nanocrystalline structure.

\section{Conclusions}

Growth interruption and $\mathrm{H}$-plasma exposure on stacking layers has been found to be an effective technique to control the hydrogenation in $\mathrm{Si}$ dangling bonds and to modulate the structural network in $\mathrm{Si}: \mathrm{H}$. Widening of the optical gap accompanied by an elimination of bonded hydrogen from the network appears to be a unique feature related to hydrogenated amorphous semiconductors, which suggests nanocrystallization and quantum size effect on optical gap in a hydrogenated binary alloy. The degree of $\mathrm{H}$-plasma treatment as well as the growth temperature both have individual influences on the process of nanocrystallization.

\section{Acknowledgements}

The author is grateful to Prof. A K Barua for his support and constant encouragement during this work, which was carried out under a project funded jointly by the Bharat Heavy Electricals Ltd. and the Ministry of Non-Conventional Energy Sources, Govt. of India. 


\section{References}

Asano A 1990 Appl. Phys. Lett. 56533

Boland J J and Parson G N 1992 Science 2561304

Brus L 1984 J. Chem. Phys. 804403

Canham L T 1990 Appl. Phys. Lett. 571046

Das D 1994 Jpn. J. Appl. Phys. 33 L571

Das D 1995a Phys. Rev. B51 10729

Das D 1995b Solid state phenomena, Special volume on hydrogenated amorphous silicon (Switzerland: Scitec Publication) Vols 44-46, pp 227

Das D. Shirai H, Hanna J and Shimizu I 1991 Jpn. J. Appl. Phys. 30 L239

Delley B and Steigmeier E F 1993 Phys. Rev. B47 1397

Fortunate E, Martins R, Ferreira I, Santos M, Marcario A and Guimaraes I 1989 J. Non-Cryst. Solids 115 120

Furukawa S and Matsumoto N 1985 Phys. Rev. B31 2114

Furukawa S and Miyasato T 1988 Phys. Rev. B38 5726; 1988 Jpn. J. Appl. Phys. 27 L2207

Jang J, Koh S O, Kim T G and Kim S C 1992 Appl. Phys. Lett. 602874

Liu X, Wu X, Bao X and He Y 1994 Appl. Phys. Lett. 64220

Nama T, Okamoto H, Hamakawa Y and Matsubara T 1983 J. Non-Cryst. Solids 59-60 333

Otobe M and Oda S 1992 Jpn. J. Appl. Phys. 31 L1443

Ren S Y and Dow J D 1992 Phys. Rev. B45 6492

Shimizu I 1989 J. Non-Cryst. Solids 114145

Shirai H, Das D, Hanna J and Shimizu I 1991 Appl. Phys. Lett. 591096

Street R A 1991 Phys. Rev. B43 2454, B44 10610

Takagi H, Ogawa H, Yamazaki Y, Ishizaki A and Nakagiri T 1990 Appl. Phys. Lett. 562379

Tong S, Liu X and Bao X 1995 Appl. Phys. Lett. 66469

Tsu R, Ye Q-Y and Nicollian E H 1990 SPIE 1361232

Winer K 1990 Phys. Rev. B41 7952 